\title{
El rol de la propaganda en las campañas electorales*
}

\section{El papel de la propaganda en la formación y el mantenimiento de la unidad polílica.}

La propaganda, además de ser una "quinta columna", es un medio idóneo para mantener la cohesión popular, de informar a la sociedad de las actividades del partido político. Permite realizar acciones más consecuentes con el objetivo estratégico de alcanzar el poder político, con repercusiones inmediatas a nivel nacional, regional y mundial.

Al no existir una eficiente propaganda, las actividades políticas y electorales pueden ser ignoradas por la población apta para el sufragio.

La propaganda tiene a bien, entre otros: mantener la cohesión de las unidades políticas y de la base social; formar una conciencia política favorable al partido; además ganar y quitarle adeptos y simpatizantes a la institución política adversaria, por eso, se cree indispensable convencer a la población a partir de hechos evidentes y de una argumentación teórica simple, es decir, de fácil acceso y comprensión a la población.

En la campaña electoral se considera como arma estralégica a la propaganda y puede llegar a ser más eficaz que cualquier "misil", pero su éxito depende principalmente de los recursos humanos, de los medios y de la utilización apropiada de éstos. El éxito comienza a ser palpable cuando algunos de los objetivos de la propaganda se cumplen, por ejemplo: haber formado una opinión pública favorable o militante; haber creado confusión entre los miembros del partido

- Esic arlículo es cl resumen de un capítulo de la investigación intilulada La guerrilla factores que determinan el triunfo o el fracaso, prescnlada por Martíncz Peñate en el scminario de ciencias políticas, rcalizado en l'Universitć du Québec á Montreal, Canadá, en la primavera de 1992. Esta versión al cspañol ha sido corregida y aumentada por Guzmán Argucta 
adversario; haber producido desconfianza y minado la moral del oponente.

La propaganda siempre debe estar a la ofensiva. A la vez, no tiene que ser solo permanente, debe ser agitadora y agresiva.

En la campaña electoral no se puede hacer una distinción entre información y propaganda, porque todo acto político consumado o a punto de realizarse es un acto de propaganda.

Cualquier actividad política, por pequeña que sea y no importando la relevancia ni la trascendencia de ésta, se debe dar a conocer y hacer creer que fue una gran actividad de vital importancia. Esta táctica es por lo general subestimada o no tomada en cuenta por algunos políticos, debido fundamentalmente a su desconocimiento del impacto psicológico que se puede lograr en la población, y porque otros dan más o única importancia a las grandes actividades electorales; cuando esta situación es sintomática es porque se ha caído en o se privilegia la propaganda sensacionalista.

La propaganda al ser falaz pierde credibilidad ante la población, algunas personas consideran que cierlos embustes podrán ser magistralmente utilizados y, que únicamente se emplearán como último recurso y en casos verdaderamente excepcionales, con el fin de confundir al partido adversario.

Es necesario destacar que la desinformación tiene por objeto engañar al enemigo en lo que concieme a su apreciación de las acciones electorales, y para lograrlo se le presentan falsas pistas e informaciones ficticias, pero se le hace creer que son auténticas y fidedignas.

Por otro lado, la contra-propaganda apunta a disminuir el efecto de la propaganda enemiga.

Se debe tener en cuenta que los partidos que disponen de grandes recursos económicos, tienen a su favor los medios de desinformación sofisticados y modernos, mientras que los de los partidos populares por lo general son artesanales y rudimentarios. En una campaña electoral, la creatividad y la imaginación pueden ser más potentes que la tecnología de punta.

En efecto, las técnicas y métodos populares son poderosos siempre y cuando se sepan utilizar mesuradamente de acuerdo con un plan propagandístico, el cual será el cuademo de bitácora que dirigirá el combate contra todos los objetivos escogidos y que, a la vez, sea flexible para que se pueda incorporar la planificación de alaques contra blancos que aparezcan en el transcurso de la campaña. Asimismo se suele conjugar las lécnicas de contra propaganda y desinformación, porque éstas son idóneas y efectivas para dividir, crear la envidia, la discordia, el descontento, y para desmoralizar al partido adversario. 
Se distingue tres tipos de propaganda:
A. La blanca
B. La negra y
C. La gris

Las más importantes son, sin embargo, las dos primeras.

\section{A. La propaganda blanca}

Es la oficial del partido y emplea, constituida, entre otros, boletines, periódi$\cos$, revistas, transmisiones de radio, televisión, etc. Se encarga de mantener a la población informada, asimismo de restar clientela electoral a los demás partidos.

Este lipo de propaganda — cuando es abundante y variada - es utilizada para "intoxicar", es decir, proporcionar falsas pistas y erróneas informaciones a los partidos políticos rivales. "La intoxicación consiste en hacer creer al adversario lo que es necesario que él crea para ser siempre sorprendido por el suceso, por la realidad, para que tenga constantemente una vista falsa de la situación, a fin de que ella lo induzca a llevar su guerra política ciega, luego paralílica"!.

\section{B. La propaganda negra}

Siempre trata de parecer auténtica, pero en esencia es todo lo contrario. En apariencia no emana del partido que la patrocina, sino de sectores independientes o de grupos anónimos que trabajan para el partido, es decir, que emana de fuentes clandestinas o de órganos aparentemente independientes. ARENA, por ejemplo, se sirvió del ILYD de Kirio para hacer la propaganda negra contra el FMLN y su fómnula presidencial en 1994. De esa manera ARENA hacía la blanca y el ILYD la negra.

Por otra parte, para que durante el desamollo de la campaña elecloral la propaganda sea verdaderamente un arma estratégica, es primordial entre otras, tener una organización donde la estructura sea, de preferencia, de pequeños equipos, de fácil movilización. La cual sería saludable que la conformaran cinco militantes partidarios, cada uno con sus propias responsabilidades bien definidas, por ejemplo, perifoneo, pinta, pegas, distribución de volantes, calcomanías, etc.

En la organización debe reinar un espíritu de cuerpo, para hacer posible el trabajo, es preciso fomentar la crítica y la autocrítica, no solo en los equipos de propaganda, sino que también es necesario efecluarla en lodos los niveles partidarios. Además, el trabajo realizado por los equipos debe ser evaluado regularmente a fin de cada vez mejorar más. 
La propaganda, además, es un medio que garantiza el mantenimiento de la unidad y la cohesión del partido.

La propaganda debe ser elaborada según el sector, gremio, capa o clase social, etc., al cual se dirige, tomando en cuenta también la coyuntura particular y concreta. La forma o estilo (fundamentalmente el discurso) debe cambiar de acuerdo con la situación presente y con los blancos escogidos, pero el contenido original no se modificará, será el mismo. De tal suerte que la propaganda podrá responder más adecuadamente a los objetivos iniciales.

La campaña de propaganda proselitista debe ser permanente y planificada de manera objeliva y con minuciosa precaución. Los que consideran que la propaganda sólo se justifica en tiempos de guerra y de elecciones políticas, cometen un grave error estratégico, debido, entre otros factores, a la formación militar o proselitista electoral de quienes así piensan. El partido político debe estar siempre dispuesto a contrarrestar la desinformación.

\subsection{La agitación}

Es un recurso auxiliar e imprescindible en la propaganda. A diferencia de ésta, que puede difundirse a través de los medios de comunicación, la agitación es por excelencia una acción que se ejecuta de viva voz ante grupos numerosos.

Los estudiosos afirman que el propagandista -en parte porque se ubica en los niveles superiores de la organización política- domina todas las ideas de la campaña, es decir, el todo y las partes de la estralegia y, en su momento, las comunica a pequeños grupos de colaboradores, que luego las hacen públicas.

Los agitadores, en cambio, dominan una idea o un conjunto muy reducido de ideas, correspondientes a la táctica de cada momento, proporcionadas por los propagandislas, y las comunican a grandes conglomerados, mediante acciones en la calle o en la plaza pública.

La aclividad agitaliva permite alcanzar efectos progandísticos apreciables, siempre que el partido cuente con las personas idóneas, en número suficiente para actuar con rapidez y efectividad entre la población.

Hay una relación de complementariedad entre propagandistas y agiladores. Los primeros planifican la estrategia y la táctica de la propaganda y formulan los mensajes para cada período y momento; los segundos divulgan entre todos los estratos de la población las consignas y las líneas específicas de las informaciones y orientaciones que al partido le interesa poner en conocimiento de todos los posibles votantes.

Para las organizaciones polílicas, cuyos recursos económicos son limilados, la labor de agitación puede asegurar buenos resultados a bajo coslo. 


\subsection{La aristocracia intelectual}

Por otro lado, se deben evitar en la campaña electoral los discursos de plaza pública ofrecidos por la "aristocracia intelectual", quienes juegan a "pastores" de los analfabetos, de los pobres, de los desempleados y de los trabajadores.

La "aristocracia intelectual" por lo general está conformada por burócratas de organizaciones en supuestos partidos de izquierda, lecnócratas de organismos internacionales o regionales, diplomáticos, catedráticos universitarios, o miembros de fundaciones o institutos de investigación que, en la gran mayoría, son financiados por los países industrializados.

Estos "sabihondos" no tienen en lo absoluto la capacidad moral para hablar sobre las reivindicaciones populares; de todos modos, si lo hacen, tienen el cuidado de que sus discursos no vayan más lejos de lo que piensan las personas, instituciones u ONG(s) que los financian (léase patrones), ni para ir a darles cátedra acerca del hambre, desnutrición, pobreza, de la falta de vivienda, etc., a las personas de escasos recursos económicos.

La mayoría de estos intelectuales se ubican en la cima de la montaña, estos "pensantes" deberían bajar del Olimpo hacia la "Ilanura". Napoleón Bonaparte, parafraseando un fragmento de el Príncipe, de Nicolás Maquiavelo, decía "las luchas se aprecian y comprenden mejor desde la llanura que desde la cima de la montañạ".

\section{La propaganda: forma y contenido}

La propaganda tiene por objeto modificar la opinión del sector de la población al que ha logrado engañar el partido contrincante, asimismo, proporcionar a la población información novedosos análisis e interpretaciones de la realidad nacional en las que la gran mayoría no ha pensado y a las cuales muy pocos tienen acceso.

La propaganda es considerada fundamentalmente ideológica, porque se propone, entre otros, la propagación de ideas, generar opiniones, creencias, profesiones de fe. En términos formales se diferencia de la publicidad en que ésta busca el beneficio económico y aquella busca adeplos, simpalizantes, seguidores, militantes, personas dispuestas a darle su volo.

En realidad la propaganda y la publicidad se complementan y se entrelazan, porque la aceplación de un producto o servicio en el mercado (objetivo de la publicidad) es equivalente a la aceptación de un candidato por el electorado (objetivo de la propaganda) y ambos propósitos se alcanzan mediante el empleo de técnicas más o menos parecidas.

Por otra parte, la propaganda electoral atacará las actuaciones o las ideas de 
los individuos $-y$ no a las instituciones-, con seguridad existen personas honeslas, vacilantes o descepcionadas de sus dirigentes políticos, etc., que se pueden reclutar y hasta obtener su cooperación. En caso conlrario, igualmente se sembrará la desconfianza y la discordia en las filas adversarias.

No se deberá atacar a las instituciones o similares porque, cuando se hace, cada miembro, funcionario o militante se sentirá agredido o herido $\mathrm{y}$, en lugar de ganar un simpatizante al partido, se le hará el favor gratuito de conseguirle un aljado más al adversario político. Inclusive no se debe atacar a un partido determinado, sino "a sus malos dirigentes", a los corruplos, demagogos, etc.

En la dirección y planificación de la propaganda electoral, se debe seleccionar a personas idóneas, como en todas las aclividades políticas. Se escogerá a militantes que hayan adquirido experiencia práctica en esta tarea, porque, desde pegar un cartel en un poste de alumbrado eléctrico, hasta pintar una piedra que se encuentra en un paredón que esté a la orilla de una carretera, es un arte. Asimismo, se elegirá a profesionales que no formen parte de la "aristocracia inteleclual", porque estos últimos hablan y escriben mucho pero no pasan a los hechos. El escogimiento se efecluará principalmente entre las profesiones siguientes: psicología, sociología, publicidad, periodismo, ciencias políticas y ciencias de la comunicación.

Se formará el equipo de propaganda electoral, el cual devendrá el responsable de esta importante y estratégica actividad, además deberá formar a los cuadros encargados o que se encargarán de la propaganda. El equipo coordinará las actividades de información, publicidad, relaciones públicas, propaganda y agitación, lo que significa que elaborará su propio plan de trabajo para el período electoral, el cual contendrá como requisito ineludible evaluaciones para cada etapa.

En la propaganda electoral no se debe atacar al enemigo de frente, cuando éste es más poderoso. Es necesario identificar el "talón de Aquiles" del adversario y ubicar en la mira sus puntos débiles.

La sorpresa y la rapidez garantizan la eficacia de las acciones de la propaganda. Cuando se ataca, hay que golpear lo más fuerte posible y rápido, para después replegarse en seguridad hasta el próximo ataque. "La rapidez es en todo caso el factor primordial de una campaña de propaganda. Hay que "acar" continuamente revelaciones, argumentos nuevos, a un ritmo tal que, cuando el adversario los conteste, la atención del público ya estará en otra cosa" 2 .

El partido adversario puede poseer sus propias tácticas de desinformación y, en algunos casos, estas tácticas podrían ser muy costosas. Las operaciones de propaganda del partido rival es posible ubicarlas en la clasificación siguiente:

1. "La primera, que llamaremos supresión, consiste en hacer creer que una cosa que existe, no existe. 
2. La segunda, que nosotros designaremos bajo el nombre de adición, consiste, al contrario, en hacer creer la existencia de cosas que no existen.

3. La tercera, que nosotros llamaremos deformaciones, consiste en hablar de una cosa que existe, pero caracterizándola de una manera falaz; la deformación puede efectuarse sobre uno o varios elementos del objeto considerado"3.

Existen varios métodos de propaganda electoral, pero el más directo y uno de los más eficaces es el ejercido de persona a persona, es decir, individualmente, en el que cada militante debe "pasar la voz" el mayor número de veces posible a personas escogidas, ya sea a colegas de trabajo, de estudio (es decir a individuos que puedan influir a otros), etc.

En cada ciudad o pueblo, por pequeño que sea, siempre hay personas en determinados lugares que juegan un rol importante y notable en la formación de la opinión pública local, la barbería, el salón de belleza, la farmacia o botica, la iglesia, la casa comunal, el comedor o restaurante, la venta de licores o bar, etc. Que esta propaganda se llame "negra", "blanca" o "gris", no importa, todo depende de los objetivos que se persigan en la planificación de la misma.

En las actividades electorales de grandes proporciones, el partido político no debe pasar por alto las informaciones que puedan brindar los miembros del servicio de inteligencia, así como los datos obtenidos de fugas de informaciones, por los elementos del partido adversario que son propensos a entregar datos importantes, como resultado del consumo de alcohol, drogas, etc. Sun Tse hablaba en estos términos: "Hay que mantener relaciones secretas con los elementos más viciosos del enemigo a fin de servirse de ellos para lograr objetivos, reunirlos con otras personas viciosas" 4.

Los partidos políticos deberían contar con una organización de "inteligencia", que recabe información acerca de los adversarios. Dicha información debe provenir de tòdas las fuentes posibles para luego confrontar las distintas versiones, a efecto de que el adversario no influya con su desinformación. El organismo de inteligencia, algunas veces, cursa informaciones falsas a sus equivalentes de otros partidos. Siempre hay que confirmarlas.

Las tareas del servicio de inteligencia son fundamentalmente las de recabar informaciones, confundir al partido contrincante, sembrar la discordia, etc. "Mantener espías en varios lugares, informarse de todo, no se debe descuidar nada que pueda llegar a no conocerse; pero cuando lú eres informado de alguna cosa, no la confíes indiscretamente a tus cercanos" 5.

El órgano encargado de la propaganda debe distribuir entre sus miembros las lareas de acuerdo con la operación o actividad por realizar, a partir de las habilidades y capacidades de cada uno. Hay partidos políticos que prefieren los campos pagados en los periódicos, así como espacios en los canales de televisión. 
No se está contra la utilización de esos medios costosos, al contrario; sólo que se debería también ulilizar los medios populares para hacer propaganda.

Se debe, además, componer o concebir un ritmo musical y canto que servirá de distintivo o de himno del Partido, para escucharlo y cantarlo no sólo en las manifestaciones, sino en todas las ocasiones propicias. El himno debe ser dinámico, simple y corto, con un ritmo que incite o estimule el sistema nervioso a "mover rílmicamente el cuerpo".

Las manifestaciones podrían ser encabezadas por una orquesta o conjunto (que no sea numeroso) donde los tambores resalten y las trompetas se escuchen claramente, las melodías que se inlerpreten podrían tener un ritmo de marcha militar, tropical o ranchero, con el fin de provocar, excitar a los participantes; de esta manera se busca sincronizar masivamente el apoyo creciente al Partido. Por otra parte, las demostraciones de fuerza no son por otro lado siempre violentas. Acordémonos de la procesión de farolitos organizada por la Universidad Centroamericana "José Simeón Cañas" (UCA), los 15 de noviembre en ocasión de los aniversarios de la masacre de los seis sacerdoles jesuilas y dos empleadas, comelida por la Fuerza Armada de El Salvador, en 1989. La procesión es de reflexión y recordatorio de los mártires, los miles de hombres y mujeres que marchan religiosamente desprenden una impresión de recogimiento, pero también de polencia, más convincente que si fuera una manifestación con consignas y grilos6.

Los discursos de algunos políticos de América Latina lienen fama internacional, no precisamente por su contenido, sino por su extensión, los cuales son por regla general demasiado largos (algunos de varias horas), por consecuencia eslos son usualmente aburridos y fastidiosos. Para los asistentes a los mitines o reuniones políticas que escuchan en un acto de esta naluraleza a más de un político hacer un discurso, resulta una verdadera tortura escucharlos mientras se está de pie y a pleno sol. Es preferible que los mitines no duren más de una hora, las ideas deben ser claras y concisas y sin ser demasiado largas y complicadas de asimilar. Lo más importante es condensar las ideas, porque éstas tienen más fuerza de impacto 7.

El "mitin" o concentración pública debe ser organizado como un espectáculo, con banderas y colores vivos que induzcan al optimismo, con música alegre y melodiosa, buen sonido, coheles, de noche, buena iluminación del acto, no vestir con descuido, buen manejo del idioma al hablar, con slogans o consignas que inviten a la acción, a derrotar al adversario.

Los oradores que intervengan ante las multitudes deben estructurar un solo discurso y desarrollar cada uno la parte que se le haya asignado, sin tocar temas que hayan sido o que serán abordados por otro orador, sin excederse del tiempo acordado. Deben organizarse, además, "brigadas de aplauso" para los oradores, 
al terminar el acto saludar con apretones de mano, sonrisas y peticiones de apoyo personal.

La propaganda tiene diferentes instrumentos o medios de distinto alcance, a saber:

\section{El comunicado de prensa}

Es un texto que contiene información clara, precisa y destacada, la cual se entrega a los medios de comunicación con la intención de que se publique. El comunicado debe conlener una información importante para el Partido y, a la vez, debe resultar interesante a los medios de comunicación para que sea publicada. Se debe tener cuidado de no caer en el vicio de enviar a los medios, comunicados de prensa irrelevantes, puesto que esta práctica le restará seriedad y credibilidad a la información partidaria.

\section{La conferencia de prensa}

Se convoca cuando se tiene una información trascendental y crucial por comunicar. Se debe preparar un texto parecido a un comunicado de prensa, que contenga información fundamental de lo que van a informar los dirigentes del partido, para distribuirlo a los periodistas después de la ronda de preguntas y respuestas que sigue a la conferencia de prensa. El texto debe citar con exactitud las palabras y mensajes de los representantes partidarios.

\section{El periódico}

Es el órgano oficial del partido. Es deseable que por lo menos circule entre los activistas del partido y representantes de la prensa nacional e internacional. Las informaciones y arlículos deben ser ilustrados con folografias y caricaturas, los titulares de las noticias deben hacer llamados a la acción y mantener el optimismo.

Las caricaturas y folografías no deben repetirse por falla de nuevas, debe evitarse la impresión de falta de actualización.

El formato del periódico no deberá ser sobrio, sin dejar de ser serio y objetivo en sus análisis. "Lenin confiaba sus artículos al Pravda; Goebbels dirigía personalmente dos periódicos; un cotidiano, l'Angriff, y un semanario, Das Reich. Mussolini sobre todo, ex-periodista de Italia, imponía a los periódicos no solamente la censura y las orientaciones, a los artículos y a los títulos, sino que también, él indicaba el número de caracteres..." " 


\section{El folleto}

Es constituido por informaciones apoyadas con ejemplos concretos, particulares y específicos y debe contener expresiones populares, sin descartar parábolas bíblicas, para aclarar con mayor precisión la información. Se recomienda incluir dibujos y fotos, porque un folleto lleno sólo de letras no es atractivo ni agradable al cuerpo electoral. Su circulación es de preferencia en las fábricas, escuelas, Universidades y colectividades en general. Lo ideal es que este lipo de publicaciones tengan periodicidad y que incluyan colaboraciones de las bases partidarias.

\section{La radio}

Es un medio que permite informar colidianamente a la población de las actividades del partido político.

"En el reporte del 28 de junio de 1940, se ve a Goebbels que continúa a subrayar los resultados obtenidos: "El ministro declara que si se procede a un estudio global de nuestras emisiones - de propaganda - radiodifundidas y su eficacia, igual que sobre el plan diplomático, se descubre que las emisiones han reportado un triunfo total que aquellas que han contribuido poderosamente al hundimiento de las fuerzas enemigas"9.

\section{El volante}

Es una página en la cual se informa y denuncia de una manera entretenida, simple y breve. Generalmenle, se distribuye de mano en mano, en lugares muy frecuentados, por ejemplo, en un mercado, en una parada o terminal de autobuses, a la salida del cine o iglesia, en una manifestación o mitin político, en una fábrica o escuela, o de puerta en puerta 10.

\section{El cartel}

No es necesario que sea obligadamente hecho en imprenta ni, mucho menos, sofisticado, porque cuando no se tienen los medios ni recursos para imprimirlo con rayos láser, se debe usar la creatividad e imaginación. Se le puede confeccionar hasta en papel periódico y pegarlo masivamente en lugares donde pueda ser leído o visto por los pasantes. Debe estar pegado en lugares donde no sea fácil para el partido rival y sus activistas destrozarlos, de preferencia sobre muros, postes telegráficos y de electricidad.

El cartel debe contener mensajes breves, claros y precisos, los caracteres deben ser legibles y apreciables a distancia, porque su lectura debe hacerla el transeúnte, inclusive sin detenerse. 


\section{El periódico mural}

Puede ser una pizarra, una tabla, una pared, etc. El cual sirve para informar, orientar y educar, entre otros. Se instala en lugares de trabajo, estudio, ocio, etc. El periódico mural está constituido principalmente por volantes, carteles, caricaturas, poemas, páginas de periódicos, avisos y chistes alusivos a la campaña electoral.

\section{Las pancartas}

Son confeccionadas por lo general en tela (particularmente en mantas). Para que tengan visibilidad, las letras deben ser de color claro cuando el fondo es oscuro (y viceversa). Las pancartas en muchos de los casos son utilizadas en las manifestaciones y concentraciones políticas. El mensaje debe ser corto, de impacto y escrito en letras grandes.

\section{Las pintas}

Representan una de las mejores armas de la propaganda, siempre y cuando se sepan formular con el mensaje adecuado y hacerlas en lugares idóneos. Muchos de los partidos consideran que las pintas solo se hacen durante las campañas electorales y en ocasión de efemérides. Las pintas se deben hacer tanto en "invierno" como en "verano".

Los lugares propicios para hacerlas pueden ser las orillas de las calles, los caminos y veredas, sobre piedras, aceras, calles pavimentadas, paredes, etc. Por ejemplo, si se hace una pinta a la orilla de una calle, será vista por los habitantes del lugar por más de una vez a la semana; si ciertas personas pasan todos los días por esa calle para ir al trabajo, aunque no se detengan a leerla o verla, el impacto será aún más fuerte puesto que el mensaje pasa descodificado al subconsciente, con lo cual se condiciona al individuo a dar por verdadera o válida la consigna o mensaje de la pinta. "un buen truco consiste en hacer pintas en letras colosales sobre lugares poco accesibles, donde se vean de lejos y donde sea difícil borrarlos o modificarlos" 11.

Durante el conflicto armado en El Salvador en el país habían muchas pintas, alguien dijo en esa época que todo El Salvador, era "un inmenso periódico mural". Esto se debía, en buena medida a que la prensa en general estaba influida por el gobierno y las organizaciones populares opositoras carecían de medios de comunicación masiva. 


\section{El Ilbro}

Es un excelente vehículo de propaganda, tanto a nivel nacional como internacional, más si éste se traduce a otros idiomas. A la vez, puede ser un buen medio de formación política e ideológica, siempre y cuando esté escrito en forma didáctica y amena, sin palabras rebuscadas y sin academicismos.

\section{El teatro}

Es un recurso de propaganda eficaz, ya que por su medio se puede representar lo que está escondido y tergiversado; tiene un gran impacto porque representa más que imágenes, personajes que son parte de la realidad socio-política y económica. En él participan personas que, como los demás, también son víctimas de la miseria, la desnutrición, y la falta de vivienda y todos los males que necesitan corrección.

El público que aprecia las representaciones de teatro se identifica con los actores. En cada jornada teatral se debe incitar a la población a favor del partido.

El teatro, además de presentarse en las zonas pobres, mercados, escuelas, etc., debe hacer breves actuaciones en algunas reuniones políticas. El teatro, como los conjuntos musicales, es de rigor en las actividades políticas electorales para despertar la conciencia y aumentar la moral y ganar adeptos.

\section{El video}

La utilización adecuada de esle medio puede favorecer al partido. A través del video se pueden grabar en el lugar de los hechos y, con actores reales, los actos que el partido en el gobierno comele contra la población, que algunos medios de comunicación no divulgan, mucho menos critican. El video debe llevarse a los tugurios, a los cantones y caseríos; en presentaciones anunciadas con anterioridad o de manera sorpresiva, todo depende de la coyuntura y la movilidad del equipo de propaganda electoral responsable de este medio.

\section{El Sondeo}

Es bueno mencionar que existen lécnicas de propaganda como los sondeos, las relaciones públicas, la publicidad, el marketing político, los cuales, en la versión moderna, pueden ser utilizados al margen de la guerra psicológica. En la actualidad estos recursos constiluyen medios de imprescindible conocimiento, aplicación y manipulación para acluar con mayor eficacia y oblener el triunfo electoral.

Ahora es indispensable estudiar seriamente la opinión pública a propósito de 
un personaje o un partido político en particular, para elaborar o modificar la estrategia de la campaña electoral y adecuarla de una manera más realista y objetiva, es decir, sobre datos concretos, para no caer en el error de improvisación ni en aventurerismo. No se pueden "dar palos a ciegas", los golpes deben ir bien dirigidos, para que tengan un buen efecto. El estudio en mención requiere que se tome en consideración el aspecto psico-social.

Para conocer sobre los efectos de la propaganda, de la publicidad, de las relaciones públicas y del marketing político en una guerra psicológica o en una campaña electoral, será necesario no solamente hacer un llamado al análisis socio-político y al análisis psico-social, también es ineludible efectuar sondeos a propósito de los objetivos.

Los datos que se obtengan del sondeo más los análisis pertinentes servirán para poseer un conocimiento objetivo de la realidad y saber si la estrategia utilizada es apropiada o no. Se estará en condiciones, por el hecho mismo de decidir mantenerla intacta o si ella responde bien a las necesidades, es decir, se le podrá aplicar los correclivos que se imponen.

Los sondeos deben realizarse, pero en caso de no poder efectuarlos por motivos o inconvenientes fuera de control, simplemente se utilizarán aquellos que realicen otros partidos o instituciones. De todas formas, todo sondeo que se pueda utilizar, es indispensable conocerlo y estudiarlo minuciosamente.

Los sondeos se han convertido en importantes en el juego político electoral, al punto que es permitido afirmar que son vitales para los partidos políticos. Esto les permite, en efecto, saber con anterioridad su grado de popularidad, de aceptación o de rechazo de la población, al liempo que ayuda a comprender las medidas de enderezamiento necesarias a través de los medios de comunicación.

A la población, los sondeos le permiten conocer más sobre los partidos polílicos. Por otro lado, los sondeos sirven para saber el porcentaje de personas que no han tomado partido o que están indecisas, porque éstos tendrán también prioridad en el delineamiento de la estrategia de la propaganda, con el fin de atraerlos, porque en muchos casos son los indecisos los que delerminan el lado hacia el cual se ha de inclinar la balanza política.

Por otra parte, los medios de comunicación colectiva interpretan los resultados de los sondeos para hacer sus propios análisis, a veces lo hacen con la participación del público o con especialistas. En la interpretación de estos resultados hay dos márgenes, uno para consumo interno, que servirá, como ya hemos dicho, para modificar, rehacer o formular la estrategia de propaganda electoral y, el otro margen, para consumo externo, este último es el que se ocupará con fines propagandísticos.

Los resultados de los sondeos se aprovecharán para extender el debate a 
favor, tomando en cuenta para ello las opiniones de una parte de la población en la discusión política.

\section{EI Marketing polílico}

Los sondeos y el markeling político, con los medios modernos de comunicación, han venido a cambiar el rol tradicional que tenían los partidos, pero a pesar de estos cambios evidentes, algunas organizaciones y partidos persisten en emplear las técnicas de las décadas pasadas, en las cuales ellos se formaron y aprendieron a utilizar. "El marketing político no es más noble, ni menos noble, que el marketing comercial. Su naturaleza es idéntica: "se trata de la puesta en práctica de los medios destinados a influenciar de modo favorable las actitudes y los comportamientos de los públicos a los cuales se dirige el producto". La diferencia radical reside en uno de los elementos del marketing mixto, el producto. En un caso, se trata de un objeto y, en el otro, de un hombre y de sus ideas" 12.

Los partidos políticos se convierten literalmente en productos que hay que vender, como se vende un jabón o un aparato de televisión, se deben explicar todas las bondades habidas y por haber que liene el producto; justificar por qué es el mejor del mercado y, que se vende a un precio sin "competencia", en donde el consumidor, lejos de perder, siempre gana, asimismo cualquier desembolso que el cliente efectúe es ínfimo comparado con las ganancias que éste y su familia obtendrán en un futuro próximo. Además, el cliente no solo tiene la oportunidad increible de adquirir el beneficioso produclo, sino que, como si todo esto fuera poco, tiene la oportunidad hasta de convertirse en "socio o accionista y quizás hasta directivo de la compañía".

Los líderes políticos se convierten en "estrellas o vedettes" de los medios de comunicación. La creación de su personalidad pública está regida por la empleada con los artistas.

El discurso de contenido es ya historia, fue superado para mal o para bien por la apariencia, hoy lo más importante, si se quiere ganar clientela, es la apariencia, empezando por un buen corle de pelo, que el color del traje haga juego con el color de la camisa y que la corbata contraste con el traje y la camisa. Se debe saber utilizar asimismo el mimetismo político-social, como el marketing político, éstos son complementarios en unos casos, en otros se privilegia uno sobre el olro, todo depende de la siluación que se presente. En suma, la lucha de contenido e ideológica ha sido sustituida por la lucha de forma y de apariencia.

Según estudios realizados por especialistas en la materia se puede concluir o sacar los siguientes porcentajes: 

1. La apariencia
$60 \%$
2. Gesticulación
$25 \%$
3. Contenido
$15 \%$

A manera de conclusión podemos decir que los sondeos han llegado a ser instrumentos muy importantes para la política, son verdaderos indicadores o elementos de estudio, no solamente para el partido político, sino también para la población y para los medios de comunicación, cuyos análisis o notas informativas se basan en los mismos.

La utilización de los sondeos, los debates televisados y el marketing político son ahora indispensables. Los comités de prensa y propaganda de los partidos políticos no solamente deben combinar las lécnicas tradicionales de propaganda, sino que deben funcionar lambién como verdaderas agencias publicilarias.

En este mismo sentido la práctica polílica hace evolucionar semånticamente algunos términos, como también las funciones de cierlas instituciones $y$, de no hacer los cambios en el momento y en el espacio preciso, se corre el riesgo de ir en sentido contrario.

\section{Reforzar la moral y la cohesión de su partido y disminuir la del adver- sario político.}

La formación política e ideológica, la dinámica de grupo, la crítica y la autocrílica ayudan a reforzar la moral, asimismo la cohesión. Estas actividades deben ser impulsadas y no deben quedar plasmadas decorativamente en los principios o normas del partido; muchos partidos u organizaciones dicen que realizan entre otros, la crítica y la autocrítica, pero lo que menos hacen es fomentar y cultivar este espíritu de democracia, y debido a este error se han cometido hasta asesinalos, no sólo en las bases sino que -incluso- hasla en las dirigencias de los partidos, to cual ha afectado seriamente la credibilidad de algunos líderes políticos y obviamente a las instituciones políticas que dirigen.

Estos asesinatos se han cometido porque no se ha tolerado ni respetado el derecho a discrepar ni a criticar la línea de partido u organización. Ningún líder político es "DIOS" para no cometer errores y, como simple mortal, debe admitir que no tiene infabilidad, por lo que no se justifica que sean etiquetados como Iraidores, infiltrados, tampoco que sean marginados, sancionados, expulsados, ni mucho menos asesinados, aquellos militantes que ejerzan su legítimo derecho de crítica y autocrítica. "Es necesario siempre tener en cuenta el principio unidad-crítica-unidad: es decir que la crítica debe siempre ser seguida de un período de consolidación de la unidad" 13.

Por otro lado, la propaganda, al sembrar la discordia y la desconfianza en el campo enemigo sirve para disminuir la moral, asimismo la cohesión del adversario. 
"Desde 1791, la ideología se alía a las armas en la conducción de las guerras y la propaganda se convierte en un auxiliar de la esirategia. Se trata de crear en cada uno la cohesión y el entusiasmo, entre el enemigo el desorden y el miedo" 14.

\section{Técnicas psicológicas}

La administración estadounidense ha hecho un resumen de las principales técnicas psicológicas que ha utilizado durante muchos años en América Latina y en otras partes del mundo, principalmente en Indochina y en Africa. Este resumen fue transmilido por el país que se afirma ser el defensor de la democracia y de los derechos humanos en el mundo, a la contra-nicaragüense, en un manual intitulado: Operaciones psicológicas en guerra de guerrillas. Esto indica la utilización selectiva del terror con fines propagandísticos.

Los EE.UU. aconsejan a los contras por medio del manual que "hay que asesinar (neutralizar) a los blancos juiciosamente escogidos, tales como magistrados, jueces, funcionarios de la policía y a los de la seguridad del Estado, a los jefes de los Comités de Defensa Sandinistas (CDS), etc." 15.

Las técnicas psicológicas que emplearon los gobiemos y los ejércitos salvadoreño, guatemalteco y hondureño, son las mismas que utilizaron los contras nicaragüenses contra la población civil. Es regulado por las técnicas estadounidenses descritas e ilustradas en el manual. En noviembre de 1984, por ejemplo. "Un grupo de voluntarios nicaragüenses (civiles) que iban en un camión abierto, cayó en una emboscada tendida por un cuerpo expedicionario de 200 hombres (contras). Veintidós voluntarios fueron matados, y después diez y siete fueron quemados vivos" 16 .

Las técnicas psicológicas para sembrar el terror deben ser contrartestadas con una respuesta psicológica planificada, la cual, a la vez, condene, con todos los medios disponibles y en todos los tonos para los diferentes sectores sociales, de una manera persistente, con el objeto de hacerle ver la realidad a la población, puesto que si alguien repite mil veces una mentira a olras personas, no solo terminará haciéndola creer, sino que, lo que es peor, el que la repitió ya no estará seguro de si en realidad era mentira. "La guerra psicológica puede en fin llegar a tener la calidad de un arma científica de terror, por su empleo asociado a las técnicas de la propaganda y a las posibilidades subversivas de la terapia psiquiátrica o psicoanalítica"17.

\section{Notas y referencias}

1. Pierte Nord, L'intoxication arme absolue de la guerre sub-versive, Paris, Fayard, 1971, p.6.

2. Jean-Maric Domenachc, La propagande politique: que sais-je?, Paris, Presses 
Universitaire de France, 1969, p.58.

3. Guy Durandin, Les mensonges en propagande et en publicite, Paris, Presses Universitaire de France, 1982, p.90.

4. Sun Tse, Los trece artículos sobre el arte de la guerra, Barcelona, Editorial Anagrama, 1974, p.80.

5. Ibid, p. 180 .

6. Vide. Jean-Marie Domenache, Op. Cis., p.p.74-75.

7. Cfr. Roberto Fabrega, Propaganda y sociedad, México, Inslituto de Investigaciones Sociales de la Universidad Nacional, 1961, p.49.

8. Joseph Folliet, Bourrage et débourrage de grânes: propagande, publicité, action psychologique, Lyon, Chronique social de France, 1963, p.99.

9. Otwin Buchbender, Radio humanité: les élmetreurs allemands clandestins: 1940, Paris, France-empire, 1986, p.51.

10. Cfr. V.I. Lenin, "Qué hacer", Obras escogidas en doce ıomos, Moscú, Editorial Progreso, Tomo II, 1975, p.51 ss.

11. Joseph Folliet, Op. Cir., p.96.

12. Jean-Paul Bobin, Le marketing politique: vendre l'homme et l'idée, Paris, Editions Milon Midia, 1988, p.31.

13. Pierre Graveline, Prenons la parole, Montséal, Editions Parti pris Ouvrier, 1978, p.38.

14. Jean Marie Domenach, Op. Cir., p.18.

15. C.I.A., Le manuel de la CIA: la politique d'intervention des Etats-Unis au Nicaragua, Berchem, Editions EPO, 1985, p.51.

16. Ibid, p.26.

17. Maurice Mégret, La guerre psychologique: que sais je?, Paris,Presses Universitaires de France, 1963, p.124. 